\title{
TECNOLOGIA: EXCLUSIVIDADE DE ESCOLAS MODERNAS?
}

Resumo: Este trabalho se ocupa do processo de modernização das escolas com ênfase na tecnologia enquanto requisito moderno. Utiliza-se modernização para a análise da tecnologia levando em conta a adesão à ideologia do progresso por meio da reforma tecnológica, na qual a inovação técnica tem como premissa revolucionar a escola. Parte-se da advertência na qual tecnologia não é somente uma ferramenta para a educação, nem apenas uma forma de se posicionar entre o ensino tradicional ou moderno e, portanto, pressupõe uma dimensão ética. O estudo se constrói com base na revisão bibliográfica de autores do campo educacional brasileiro, teóricos da cultura e filósofos da tecnologia. Emprestamos as concepções de Andrew Feenberg acerca do substantivismo, do determinismo e do instrumentalismo no que toca as representações usuais da tecnologia.

Palavras-chave: Tecnologia. Modernização. Escola.

\section{TECHNOLOGY: EXCLUSIVITY OF MODERN SCHOOLS?}

Astract: This work deals with the modernization process of schools with an emphasis on technology as a modern requirement. We use modernization to analyze the technology, taking into account the adhesion to the ideology of progress through technological reform, in which technical innovation is premised revolutionizing the school. It starts from the warning that technology is not only a tool for education, not even it's just a way of positioning itself between traditional or modern education and, therefore, it presupposes an ethical dimension. The study is based on the bibliographical review of brazilian researchers in education related to culture theorists and philosophers of technology. We employ Andrew Feenberg's conceptions of substantivism, determinism, and instrumentalism about the usual representations of technology

Keywords: Technology. Modernization. School.

Tecnologia é um termo que coloca em xeque o campo educacional hoje na medida em que assumimos a impossibilidade de adotar uma postura indiferente a seu respeito. Devido a realidade complexa que comporta tornou-se um conceito polissêmico, ao mesmo tempo comum e diverso entre as diferentes áreas do conhecimento. No que diz respeito a pesquisa educacional, identificamos algumas abordagens recentes no intuito de explicitar qual perspectiva associamos à tecnologia e que aspectos motivam a escolha de estudá-la a partir da sua relação com o processo de modernização das escolas.

\footnotetext{
${ }^{1}$ Mestra pelo Programa de Pós-Graduação em Educação (PPGE/UFSC), sob orientação do Prof. Dr. Elison Antonio Paim, e com auxílio do Conselho Nacional de Desenvolvimento à Pesquisa (CNPq). Endereço postal: Centro de Ciências da Educação (CED), campus Universitário da Trindade, Florianópolis/SC, CEP: 88040-900. Endereço eletrônico: <giovanna santana@hotmail.com.br>.
}

Criar Educação, Criciúma, v. 8, n¹, jan/jul 2019.- PPGE - UNESC 
Este trabalho integra uma dissertação de mestrado em desenvolvimento na área da Educação e se ocupa do processo de modernização das escolas com ênfase na tecnologia enquanto requisito moderno. Assumimos como postura ética frente à educação tecnológica advertir que artefatos resultantes de procedimentos tecnológicos também se constituem como tecnologias, sejam eles classificados como modernos ou tradicionais.

Em tese de doutorado defendida no ano de 2013 na Faculdade de Educação da Universidade de São Paulo, Michelle Prazeres apontou que ressalvas ao uso de novas tecnologias na educação básica podem facilmente ser encaradas como posições radicais, em razão da crítica incipiente do desenvolvimento tecnológico nos âmbitos das escolas, das pesquisas acadêmicas, da mídia e das políticas educacionais. No centro da sua análise estão as políticas adotadas pelo estado de São Paulo a partir do ano 2000 no sentido de modernizar as escolas públicas via novas tecnologias digitais capazes de rede. Decorre da extensiva produção literária sobre a aplicação das tecnologias da informação e comunicação (TICs) nas salas de aula, promovidas tanto pela mídia quanto pela academia, a escolha da pesquisadora em tratar da incorporação das TICs mediante as fontes documentais, dentre elas produções acadêmicas, projetos estatais, reportagens em jornais, bem como relatórios da empresa Microsoft. No conjunto de fontes encontram-se 86 documentos, dentre eles 17 matérias publicadas no portal da Secretaria de Educação do Estado de São Paulo, 34 notícias publicadas nos jornais Folha de São Paulo e O Estado de São Paulo, artigos acadêmicos, teses, dissertações, e nos Relatórios de Cidadania Corporativa da multinacional Microsoft, o programa Aluno Monitor (2004-2011).

Com o objetivo de explicar os motivos para valorização do uso de TICs, a autora selecionou quatro protagonistas em disputa na projeção do discurso sobre tecnologia e escola, a saber: o Poder Público do Estado de São Paulo, a empresa multinacional Microsoft, os jornais Folha de São Paulo e O Estado de São Paulo e a Universidade, concentrada em produções da área de Educação e Comunicação. Dessa forma, o texto em análise foi estruturado com base em três categorias de representação das TICs: o (1) impacto referente aos efeitos da tecnologia na 
educação, as (2) tendências direcionadas para constatação de avanços e melhorias e a (3) linguagem, concernente à tecnologia como expressão de uma época.

De acordo com a orientação metodológica para um olhar relacional, a noção de campo emprestada de Bourdieu tornou-se determinante para a pesquisa, pois foi empregada tanto como objeto quanto ferramenta teórica. Por campo remete-se a uma rede de relações sociais com leis próprias e disputas internas, que dispõe de relativa autonomia em seu domínio, onde agentes, sujeitos e indivíduos atuam segundo suas posições sociais e conforme as regras estipuladas pelo jogo. Nas palavras da jornalista e educadora, "a noção de campo é ponto de partida, e ao mesmo tempo, de chegada para esta Tese" (PRAZERES, 2013, p. 21). Buscou, portanto, encontrar a identidade do campo educacional contemporâneo com recorte na educação escolar pública a partir da sua relação com o campo "ciber-culturalmidiático-tecnológico", compreendendo que esta correspondência tem como produto as políticas de modernização escolar no estado de São Paulo.

Na menção à cibercultura, termo homônimo à obra de Pierre Lévy (2001), identifica o conceito representativo do espírito contemporâneo, considerando a projeção da inovação tecnológica e do progresso como valores universais. Em virtude da condição anterior, aparecem contemplados na cibercultura os universos materiais e simbólicos "presente nos indivíduos, nas instituições e no modus operandi contemporâneos" (PRAZERES, 2013 p. 23) que, por sua vez, correspondem às novas formas de produção e socialização intercambiadas pelo advento do ciberespaço. ${ }^{2}$ Estes seriam alguns aspectos iniciais e necessários para a compreensão da terminologia "ciber-cultural-midiático-tecnológico" composta pela autora no decorrer de sua tese.

Por constatar um universal tecnológico representado pelos valores dominantes da cibercultura, a pesquisadora propõe como hipótese revisar a autonomia do campo educacional na medida em que ele na sua inter-relação com os demais campos promove um repertório de valores em comum. Suscetível às forças

\footnotetext{
2 Ciberespaço, derivado etimologicamente da cibernética, é a definição dada para uma área de intercomunicação projetada por uma rede global. Ainda que demande o armazenamento físico pela matéria da computação e da tecnologia, o ciberespaço é em maior parte constituído pelo fenômeno da virtualização, amplamente estudado pelo filósofo e sociólogo Pierre Lévy.
}

Criar Educação, Criciúma, v. 8, no1, jan/jul 2019.- PPGE - UNESC 
onipresentes da cibercultura, que emanam de diferentes campos sem necessariamente demandar um emissor central, a pesquisa considerou repensar a definição do campo educacional em evidência a partir da sua condição heteronômica.

Dentre as contribuições da tese para este estudo torna-se conveniente reiterar àquelas que decorrem das perguntas:

[...] existe, de fato, um processo de modernização da educação em curso? O que o caracteriza? Como ele é representado por diferentes campos sociais interessados na sua construção? Seria correto nomeá-lo enquanto processo de modernização? Existe diferença em relação ao que se chama de inovação? Ou ainda em relação ao que se denomina reforma? (PRAZERES, 2013, p. 20)

Sua análise advoga em favor da modernização como forma mais precisa de nomear essas transformações em curso, opção expressa desde o título da tese em que se propõe investigar o fenômeno da moderna socialização escolar, anexo ao subtítulo "um estudo sobre a construção da crença nas tecnologias digitais e seus efeitos para o campo educacional". Todavia, vale destacar, o título da tese é antes um recurso retórico em teste que um repertório de ações ou implementações práticas que buscou problematizar.

Ao longo da sua pesquisa, as nomenclaturas reforma e inovação foram empregadas com ressalvas de modo que a escolha em favor da modernização não implicou em um descarte dos termos anteriores; haja vista a relevância de ambos no processo de seleção e análise documental. A autora menciona dentre as palavraschave que resultaram na seleção documentos relevantes para a pesquisa, "inovação" e "reforma" como os mais representativos no que condiz aos relatos de usos e às representações das TICs aplicadas na educação básica. Outras palavras empregadas na seleção foram "mídias", "moderno", "modernização", "computador" e respectivamente "notebook" (PRAZERES, 2013, p. 36).

Via de regra, trata-se de uma educação "modernizada, inovada e reformada" por intermédio das tecnologias digitais, mesmo que na representação dos campos em análise a inovação esteja estritamente pautada pela instrumentalização das novas tecnologias. Desse modo, a diferença estabelecida por Prazeres (2013, p. 99- 
100) relativa à inovação partiu da observação de que o termo não é refletido em sentido amplo, pois a inovação poderia se fixar "[...] no abandono da ideia de progresso e no avanço do entendimento das tecnologias como movimento das esferas sociais, culturais e políticas e não apenas em termos de "inovação" da técnica por si mesma".

A pesquisa também identificou a falta de precisão entre as terminologias "moderno", "inovador" e "transformador", especialmente no que se refere às produções do Poder Público, da empresa Microsoft, dos jornais Folha de São Paulo e O Estado de São Paulo. Nos documentos avaliados, transformação não se traduz por uma mudança de ordem estrutural, embora a palavra revolução seja empregada como seu sinônimo. Desse modo, utiliza-se transformação no sentido condizente ao impacto da inovação que conforme posto anteriormente permanece restrita ao carácter técnico. Segundo a avaliação de Prazeres (2013, p. 153) o processo de modernização e suas estratégias não promovem "[...] - ao contrário do que preconiza uma ideia presente em documentos dos quatro campos analisados nesta Tese - uma revolução. Buscando classificá-las, a melhor terminologia parece ser a de uma reforma tecnológica".

Em paralelo com as reflexões de Ghanem (2013 apud PRAZERES, 2013, p. 154) adverte para um conjunto de medidas reformistas em consonância com lógicas globais, que veiculam ideias de carácter impositivo e homogêneo, as quais também "desfrutariam de sustentabilidade financeira e condição de visibilidade". Relatou que durante sua trajetória do doutorado, as parcerias público-privadas da multinacional Microsoft cresciam através de contratos firmados com os Governos Estaduais, como ocorreu em 2009 no Rio Grande do Sul e em 2013 no estado do Paraná.

No entanto, a tese associou o desenvolvimento desses projetos hegemônicos ao crescimento dos softwares livres ou abertos no país, particularmente empreendido pelas políticas de âmbito federal durante a governança presidencial do Partido dos Trabalhadores. ${ }^{3}$ Sem pormenorizar o que distingue os softwares livres dos proprietários e, por conseguinte, desconsiderando as rupturas ideológicas e

\footnotetext{
3 Embora não aprofunde a discussão sobre o tema no Brasil, cita como "expoente" da modernização empreendida por recursos livres ou abertos o Projeto Brasileiro sobre Recursos Educacionais Abertos (REA).
}

Criar Educação, Criciúma, v. 8, n¹, jan/jul 2019.- PPGE - UNESC 
éticas relacionadas às licenças públicas, à distribuição dos programas e ao acesso do código-fonte, a pesquisa preconizou que ambos os projetos são "legítimos representantes do discurso de modernização" afinados com os valores da cibercultura, "[...] visto que apregoam a inclusão digital como solução, seja feita com ferramentas livres ou proprietárias" (PRAZERES, 2013, p. 84).

Mesmo que a pesquisa aponte para a predominância dos softwares proprietários nas políticas educacionais, e ainda mencione a oportunidade destas empresas instaurarem projetos pedagógicos "contra a pirataria", em favor da "privacidade individual" e da "segurança dos usuários" - o que chega a configurar uma bandeira em comum entre as indústrias que comercializam licenças educacionais exclusivas - torna-se necessário contrastar esse discurso com seus críticos, no intuito de ressaltar as possibilidades de ações contra-hegemônicas nos domínios da cibercultura.

Pois é justamente no argumento da privacidade individual e da segurança dos usuários que recaí boa parte das críticas dos desenvolvedores, usuários e ativistas dos softwares livres. ${ }^{4}$ Podemos citar a exemplo as constatações de Richard M. Stallman, militante e programador do GNU General Public License (GNUGPL), criador da Fundação do Software Livre (FSF) e da Licença Copyleft. Em diversas oportunidades, Stallman denuncia a capacidade de controle dos softwares proprietários exercido remotamente sobre seus usuários, seja para coleta de informações pessoais, restrições do usuário, imposições de upgrades com vistas à obsolescência programada, dentre outras operações resultantes tanto da falta de transparência sobre a execução destes programas, quanto das ações empresariais objetivadas pelo lucro.

Evidente que os conflitos de propriedade intelectual, de segurança, liberdade e de compartilhamento das informações na rede repercutem em propostas educacionais diversas, com base em recursos abertos, livres ou proprietários. Por conta destas características, e deste quadro de projetos em disputa, utilizaremos em

\footnotetext{
${ }^{4}$ É preciso dizer que os softwares livres não se resumem ao código aberto (Open Source) e aos programas gratuitos. Portanto, o termo livre refere-se com rigor às questões liberdade do usuário e da comunidade sobre os programas. O Movimento do Software Livre teve início em 1983 e, devido as disputas internas, surgiu em 1998 o Movimento pelo Código Aberto.
}

Criar Educação, Criciúma, v. 8, no1, jan/jul 2019.- PPGE - UNESC 
diante modernização como forma de caracterizar estritamente a mercantilização da educação básica. Com isso, pretendemos levar em conta de modo simultâneo a adesão à ideologia do progresso por meio da reforma tecnológica, na qual a inovação técnica tem como premissa reinventar ou revolucionar a escola. Na esteira deste pensamento, ocorre o prognóstico da arritmia escolar perante os avanços tecnológicos, uma vez que os tecnólogos são representados em constante vantagem sobre determinação dos processos sociais, haja vista o impacto de suas inovações técnicas. Ainda que Michele Prazeres (2013, p. 99) não disponha da discussão sobre determinismo tecnológico para avaliar àquilo que caracterizou como "senso comum" e "crença a favor das tecnologias digitais nas escolas" é possível estabelecer alguns paralelos com o conceito.

A tese em diálogo concebeu um diagrama das crenças nas novas tecnologias por meio do mapeamento de zonas simbólicas de convergência entre os quatro campos selecionados, considerando, em primeira instância, o trânsito dos agentes discursivos (alunos, professores, diretores, pesquisadores, jornalistas e representantes do Poder Público) em mais de um dos campos. Discorreu, portanto, sobre o estabelecimento de uma ambiência favorável para valorização das tecnologias digitais mediante o repertório de representações comuns e consensuais fundamentadas nos valores da cibercultura. São eles: inclusão, velocidade, conectividade, eficiência, agilidade, inovação e flexibilidade (PRAZERES, 2013, p. 24).

Em resumo, as representações que dão corpo ao mito da moderna socialização escolar são construções caracterizadas pela tecnocracia e pela aposta de transformação exclusivamente por via das novas tecnologias, o que na instituição pública se converte em "uma espécie de "verniz" para escamotear outros problemas educacionais" (PRAZERES, 2013, p. 152). A mesma lógica ambiciona a "adaptação da escola ao jovem" como espaço mais atrativo para produção do conhecimento, tal qual se manifesta na América Latina o maior apelo das novas tecnologias como forma mais profícua de "ser moderno" (PRAZERES, 2013, p. 155). Mesmo em suas representações mais ponderadas, condizente às produções acadêmicas, a pesquisadora constatou o consenso acerca da incorporação irrefutável das 
tecnologias digitais nas escolas, assim como verificou nos demais campos a representação de sua inexorabilidade.

De maneira semelhante à indicativa da tese no que condiz às diferenças existentes entre as representações das tecnologias, por um lado, e seu verdadeiro potencial para conduzir as transformações sociais, de outro, Raymond Williams (2016) indicou as incongruências reducionistas difundidas pela teoria do determinismo tecnológico, em particular, num diálogo crítico com as produções do filósofo e educador canadense Marshall McLuhan. O paralelo estabelecido entre Williams (2011, p. 132) e a tese vigora de acordo com a avaliação do autor na qual "A situação real, então, não é de um determinismo tecnológico, mesmo em alguma versão refinada. A sensação de uma nova tecnologia como inevitável ou irrefutável é produto de um explícito, ou não, marketing de fortes interesses".

Conforme o autor situa em sua análise, o pressuposto básico para 0 determinismo tecnológico reside na ideia de que uma nova tecnologia emerge do experimento e da pesquisa técnica, modificando o seu entorno e consequentemente a sociedade. Cabe a nós, sujeitos alheios ao universo da produção científicotecnológica, adequarmo-nos às mudanças visto que estas apontam para o inevitável "novo caminho moderno". No entanto, em seu estudo sobre a televisão, por exemplo, Williams (2016) descreveu com detalhes a planificação e investimentos necessários para transpor uma invenção técnica para o estado de tecnologia socialmente disponível. Isso constata o critério no qual, em sua maioria, as pesquisas e os experimentos científicos ocorrem segundo finalidades previstas, 0 mesmo que dizer, são gestadas dentro de relações históricas e culturais preestabelecidas e a partir de interesses expressamente demarcados.

\begin{abstract}
Além disso, uma invenção técnica como tal tem uma relevância social relativamente pequena. Apenas quando ela é selecionada para um investimento visando à produção, e quando ela é desenvolvida conscientemente para usos sociais específicos [...] é que a invenção ganha relevância. Esses processos de seleção, investimento e desenvolvimento são, obviamente, de um tipo social e econômico geral, dentro de relações sociais e econômicas existentes e, em uma ordem social específica, são concebidos para usos e vantagens particulares [...]. Logo não se trata de uma invenção tecnológica apontando para as instituições sociais e culturais. A invenção, ela mesma foi desenvolvida, dentro das formas e possibilidades existentes [...] (WILLIAMS, 2011, p. 129-130).
\end{abstract}


Por conseguinte, compreender a tecnologia para além do reducionismo contido na concepção determinista significa ponderar sobre sua constituição social e histórica, cujo o desenvolvimento ao mesmo passo que influência é à vista disso influenciado. Nesse sentido, deu-se a escolha por não dissociar neste estudo o desenvolvimento da tecnologia da história da instituição escolar, visto que a progressão de ambas assume uma dinâmica na qual não apenas a tecnologia interfere nos processos educativos assim como própria a escola produz expectativas, ideias e representações que, por sua vez, interferem nas relações estabelecidas com as tecnologias e com a educação tecnológica de um modo geral.

Convém no momento posicionar-se em relação a questão propositada desde o título, no que se refere à associação das tecnologias como exclusividade de escolas modernas. Entendemos que este argumento tem intrínseco tanto um conceito restrito de tecnologia quanto, em determinados casos, o pressuposto dualista entre o público e o privado na educação básica. Desse modo, o ponto de partida para a discussão é a advertência na qual tecnologia não é somente um meio ou ferramenta para a educação, nem apenas uma forma de se posicionar entre o ensino tradicional ou moderno, e por conta dessas características pressupõe uma dimensão ética.

Como vimos anteriormente, o argumento em favor do determinismo tecnológico tem como pano de fundo a vinculação com a ideologia do progresso, o que acarreta na preferência notável pela novidade e por aquilo que é considerado high tech. Decorre da difusão deste pensamento na sociedade contemporânea, a tendência em referenciar a tecnologia a partir de uma condição bastante marcada pelos dispositivos tecnológicos de uso recente, dispensando um olhar de longa duração sobre o conceito, que a meu ver, encontra-se nas bases materiais que possibilitaram a democratização do acesso à escola.

A fim de citar um exemplo prático, certa vez, atuando em um curso de formação de professores envolvidos com a Educação do Campo, propus de antemão aos professores e professoras que indicassem se portavam algum artefato 
tecnológico consigo. ${ }^{5}$ Conforme o esperado, a maior incidência de citações correspondeu aos smarthphones, ao mesmo tempo que escaparam à recordação outros artigos também comuns como, por exemplo, os relógios de pulso. Essa breve experiência pôde expor de maneira significativa a tendência que Prazeres (2013) constatou acerca do encantamento pela tecnologia digital e a desconfiança para com as tecnologias do tipo analógico. Evidente que naquele contexto houve exceção e ao menos um dos participantes interveio com uma noção bastante ampliada da tecnologia, remetendo-a às vestimentas e aos materiais escolares tais como papel e caneta. Neste caso em particular, o educador já estava refletindo sobre o conceito de tecnologia, posto sua inserção na área da Filosofia e com base no posicionamento que demonstrou em favor dos softwares livres. Levando em conta esses aspectos, trabalhamos na ocasião com vistas a reconhecer a tecnologia por sua realidade complexa e com o propósito de criar possibilidades do estudo em sala de aula que dispensem a necessidade arbitrária de sua instrumentalização, uma vez que o instrumentalismo, segundo Feenberg (2010), em paralelo ao determinismo, instruí as concepções usuais e neutras da tecnologia.

Ao longo da conferência realizada em 2003 na Universidade de Tokyo (Komaba), o filósofo nova-iorquino Andrew Feenberg (2010, p. 46) sistematizou o debate contemporâneo sobre a Filosofia da Tecnologia entre duas principais vertentes que denominou autônoma e humanamente controlada. Segundo sua exposição, interpretar a tecnologia como potência autônoma, significa pressupor que seu desenvolvimento corresponde às leis próprias, sobre as quais os sujeitos alheios ao universo da produção científico-tecnológica exercem pouco ou nenhum domínio, de tal maneira que "Os deterministas acreditam que a tecnologia não é controlada humanamente, mas que, pelo contrário, controla os seres humanos, isto é, molda a sociedade às exigências de eficiência e progresso." Conforme expôs o filósofo, a eficiência e o progresso nesse contexto são apropriados enquanto valores meramente formais, porque podem estar a serviço de diferentes concepções de

\footnotetext{
${ }^{5}$ A oficina aconteceu no dia 18 de julho de 2017, na cidade de Mafra/SC, com a duração três horas e foi organizada com grupos distintos no período da manhã e tarde, contando com uma média de seis professores por turno. Os docentes atuam em escolas multisseriadas e lidam com diferentes disciplinas como Educação Física, Inglês, Matemática, Português, Filosofia, entre outros.
}

Criar Educação, Criciúma, v. 8, no1, jan/jul 2019.- PPGE - UNESC 
sociedade. Além do mais, indicou que essa forma argumentação sobreposta às ciências humanas comumente vigora na representação do avanço tecnológico como força motriz da história.

Já no instrumentalismo, a neutralidade e o domínio humano se entrecruzam. Desse modo, a concepção humanamente controlada partilha do princípio no qual sendo a tecnologia neutra em valor a intensão humana determina seu caráter "o que significa que não há preferência entre os vários usos possíveis a que possa ser posta" (FEENBERG, 2010, p. 43). Para autor essa relação neutra da tecnologia encontra-se expresso de maneira vulgar na afirmativa "armas não matam as pessoas, as pessoas matam as pessoas" corrente nas sociedades norteamericanas. Todavia, conforme o anteposto, o desenvolvimento de qualquer tecnologia acompanha interesses específicos, logo corresponde aos valores de uma dada sociedade, especialmente, às intenções de caráter hegemônico, que para Williams (2005, p. 217) traduzem-se em um complexo "de significados e valores que, vividos como práticas, parecem se confirmar uns aos outros, constituindo assim o que a maioria das pessoas na sociedade considera ser o sentido da realidade, uma realidade absoluta porque vivida".

Em contraste com as tendências neutras da tecnologia, outras duas perspectivas emergiram no esquema exposto durante a conferência intitulada $O$ que é Filosofia da Tecnologia? (2003), dentre elas o substantivíssimo e a Teoria Crítica. Esta última, em particular, relacionada ao posicionamento político teóricometodológico de Feenberg, onde se encontra na esteira dos argumentos de Herbert Marcuse.

A concepção substantiva, próxima ao determinismo tecnológico, opera a partir da vertente autônoma, mas se difere do mesmo no que toca o valor da neutralidade. Partindo da premissa de não se resume ao instrumental, segundo a interpretação substantiva "O uso da tecnologia para esse ou aquele propósito seria uma escolha de valor específica em si mesma e não apenas uma forma mais eficiente de compreender um valor preexistente de algum tipo." (FEENBERG, 2010, p. 47). O filósofo também constatou intersecções entre autores substantivistas e deterministas indicando que as nuances entre ambos costumam variar conforme 0 


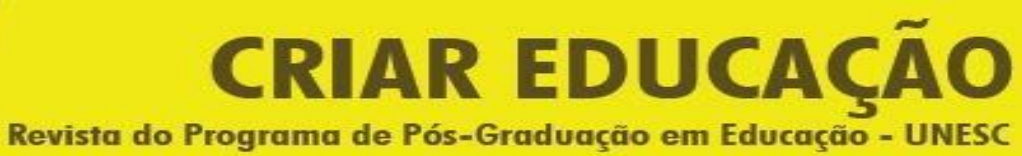

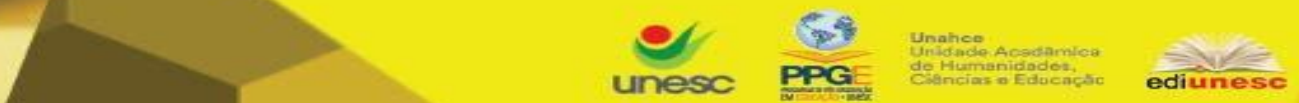

pessimismo intrínseco à primeira e o otimismo preponderante na segunda. No extremo da representação substantivista situou o Admirável Mundo Novo (1931) de Aldous Huxley (1894-1963); na tradição do determinismo tecnológico característico do século XIX, localizou pensamento de Karl Marx (1818-1883).

A Teoria Crítica, por sua vez, compartilha de algumas características ao mesmo tempo que discorda das demais interpretações nos seguintes aspectos:

Concorda com o instrumentalismo que a tecnologia é controlável em algum sentido, também concorda com o substantivismo que a tecnologia está carregada de valores. [...] De acordo com o substantivismo, os valores contidos na tecnologia são exclusivos da tecnologia. Eles incluem a eficiência e o poder, metas que pertencem a qualquer e a todo sistema técnico. Na medida em que usamos a tecnologia, estamos comprometidos com o mundo em um movimento de maximização e controle. Essa aproximação do mundo determina um estilo tecnológico de vida. Obviamente o controle humano teria pouco significado, se cada estilo de vida se fundamentasse em tecnologias e a elas executassem os mesmos valores (FEENBERG, 2010, p. 49).

O trecho acima aponta para a concepção do autor segundo a qual os valores incorporados às tecnologias são socialmente específicos, em contraposição às formas abstratas como eficiência e controle para o determinismo. Dito de outra forma, a tecnologia não proporciona apenas um único modo de vida, mas aponta para vários estilos possíveis. Nas palavras de Feenberg (2010, p. 50): "Na Teoria Crítica, a tecnologia não é vista como ferramenta, mas como estrutura para estilos de vida. As escolhas estão abertas para nós e situadas em nível mais alto que o instrumental.". Na esteira deste pensamento, partilhamos da ideia de que são nos momentos de escolhas, evidenciados pelo autor, que irrompem as dimensões éticas da tecnologia.

De maneira semelhante, o filósofo e educador Paulo Freire (2000, p. 46) inspirado pela tradição da Teoria Crítica, porém mais próximo do psicanalista Eric Fromm, escreveu que:

Quanto maior vem sendo a importância da tecnologia hoje tanto mais se afirma a necessidade de rigorosa vigilância ética sobre ela. [...] Por isso mesmo a formação técnico-científica de que urgentemente precisamos é muito mais do que puro treinamento ou adestramento para o uso de procedimentos tecnológicos. [...]. Filosofar, assim, se impõe não como puro encanto mas como espanto diante do mundo, diante das coisas, da História 
que precisa ser compreendida ao ser vivida no jogo em que, ao fazê-la, somos por ela feitos e refeitos.

Decorre da condição anterior, a necessidade de realizarmos escolhas essencialmente éticas, cujas alternativas, como vimos, são suscetíveis às pressões e aos limites impostos pelas forças hegemônicas. Ressaltamos, a partir do diálogo com o campo filosófico, a correspondência entre aspectos estruturais da instituição escolar e o desenvolvimento da tecnologia, levando em conta a amplitude do conceito a começar pela sua dimensão social e ética. Por esse ângulo nos apropriamos de algumas reflexões formuladas pela Filosofia da Tecnologia, em particular pelo viés da Teoria Crítica, com intuito de enfatizar as realidades complexas que integram as sociedades tecnológicas, referidas não apenas nos dispositivos e seus usos, mas também nos diferentes estilos de vida que possibilitam (CUPANI, 2011).

Assumimos, então, como postura ética frente à educação tecnológica advertir que os artefatos resultantes de procedimentos tecnológicos também se constituem como tecnologias, sejam eles classificados como inovares ou tradicionais. Quando ressaltamos este aspecto percebemos que é cada vez mais complicado discernir a tecnologia em nossas ações cotidianas e triviais. Relacionado à História da Educação, em especial, correlato ao processo de democratização do acesso à escola, concebemos os materiais didáticos - derivados dos livros e das técnicas de escrita - como invenções tecnológicas eminentemente modernas, quando a partir da tiragem em série promoveu-se a disseminação de uma cultura letrada. Não fosse a planificação e a exploração em torno do advento da imprensa, talvez estivéssemos mais próximos da tradição da cultura oral como forma predominante na produção do conhecimento. A suposição se dá a título de realçar que tais eventos incidem no curso da História, mas de maneira semelhante são determinados por ela.

Por fim, queremos explicitar que ao escolhemos nesta pesquisa reiterar os livros como exemplos de tecnologias nas escolas, situamo-nos na contracorrente do preceito da "inovação", subsumida no progresso e na obsolescência programada, advindas do modo produção industrial, mas igualmente influentes na produção do conhecimento contemporâneo. 


\section{Referências}

CUPANI, A. O. Filosofia da tecnologia: um convite. Florianópolis: Editora UFSC, 2011

FEENBERG, A. O que é filosofia da tecnologia? In: NEDER, R. T. (org.). Andrew Feenberg: racionalização democrática, poder e tecnologia. Cadernos Construção Crítica da Tecnologia \& Sustentabilidade. Brasília: Observatório do Movimento pela Tecnologia Social na América Latina/Centro de Desenvolvimento Sustentável, v. 1, n. 3, p. 39-51, 2010.

FREIRE, P. Pedagogia da Indignação: cartas pedagógicas e outros escritos. São Paulo: Editora UNESP, 2000.

PRAZERES, M. A moderna socialização escolar: um estudo sobre a construção da crença nas tecnologias digitais e seus efeitos para o campo da educação. Tese (Doutorado em Educação) - Pós-Graduação em Educação, Universidade de São Paulo, São Paulo, 2013.

WILLIAMS, R. Base e superestrutura na teoria cultural marxista. Tradução de Bianca Ribeiro Manfrini. Rev. USP., mar./mai. 2005, n.65, p. 210-224.

WILLIAMS, R. Política do Modernismo: contra os novos conformistas. Tradução André Glasser. São Paulo: Editora UNESP, 2011.

WILLIAMS, R. Televisão: tecnologia e forma cultural. Tradução Marcio Serelle, Mário F. I. Viggiano. São Paulo: Boitempo. Belo Horizonte: PUC Minas, 2016.

Recebido em dezembro 2018

Aprovado em março 2019 